\title{
UJI AKTIVITAS ANTIOKSIDAN SENYAWA PIRAZOLIN 3-(2- METOKSI-FENIL)-5-NAFTALEN-1-IL-4,5-DIHIDRO-1H-PIRAZOL
}

\author{
Nurlaili, Jasril, Hilwan Yuda Teruna \\ Jurusan Kimia, FMIPA, Universitas Riau \\ e-mail:jasril.k@lecturer.unri.ac.id; Nurlaili@grad.unri.ac.id \\ ABSTRACT
}

\begin{abstract}
Pyrazoline compounds are reported to have many useful biological activities such as antimicrobials, antihyperglycemia, antioxidants, anti-inflammatory, anticancer and anticonvulsants. The pyrazoline analogues of 3-(2-methoxy-phenyl) -5-naphthalene-1-yl-4,5-dihydro-1H-pyrazol were synthesized using glacial acetic acid as catalyst and assisted by microwave irradiation. The structures of the compounds were obtainedby $U V, I R$ and HRMS spectroscopy data. Antioxidant activity test using DPPH method showed that pyrazoline compound had $I_{50}$ value of $27.41 \mu \mathrm{g} / \mathrm{mL}$.
\end{abstract}

Keywords: Pyrazoline, microwave irradiation, characterization, antioxidant, DPPH.

\section{PENDAHULUAN}

Pirazolin memilki peran penting dalam berbagai sintesis senyawa heterosiklik lain seperti isoksazol, kuinolinon, tiadiazin, benzofuranon dan benzodiazepin (Jayapal dan Sreedhar, 2010) serta telah digunakan secara intensif sebagai farmakofor dalam mendesain obat-obatan maupun sinton untuk sintesis senyawa organik (Jaishree dkk., 2010). Pirazolin diklasifikasikan ke dalam golongan alkaloid tetapi jarang ditemukan di alam. Salah satu metode preparatif untuk sintesis pirazolin yang umum dikenal adalah reaksi siklisasi antara keton $\alpha, \beta$ tak jenuh atau keton $\alpha, \beta$ epoksi dengan hidrazin dan turunannya (Sakthinathan dkk., 2012).

Pirazolin merupakan senyawa heterosiklik lingkar lima yang memiliki dua atom nitrogen saling berdekatan didalam cincinnya dan hanya memiliki satu ikatan rangkap endosiklik (Bagade dkk., 2010). Pirazolin banyak digunakan dalam kehidupan sehari-hari dan memiliki nilai teraupetik yang baik (Arora dkk., 2012). Pada penelitian sebelumnya pirazolin mempunyai aktivitas biologi seperti antibakteri, antitumor, antikanker, antidiabetes, anti-inflamasi (Bagade dkk., 2010), antidepresi, antiamoeba dan antitubecular (Prasad dkk., 2010).

Pada umumnya, sintesis senyawa pirazolin dilakukan dalam 2 tahap. Tahap pertama adalah sintesis senyawa kalkon melalui reaksi kondensasi aldol menggunakan turunan benzaldehid dan keton sebagai starting material dalam suasana asam atau basa. Tahapan kedua, sintesis senyawa kalkon dengan turunan hidrazin membentuk senyawa pirazolin (Singh dkk., 2009). Sintesis senyawa pirazolin dapat dilakukan menggunakan katalis asam atau basa, pemanasan, pengadukan, dan radiasi menggunakan gelombang mikro (Azarifar dkk., 2002). Namun beberapa tahun terakhir ini penggunaan energi microwave dalam reaksi organik sangat populer karena lebih aman, ramah lingkungan (green chemistry), cepat dan menghasilkan produk yang lebih banyak dibandingkan metode konvensional. 
Senyawa pirazolin hasil sintesis dikarakterisasi berdasarkan interpretasi data spektroskopi UV, IR dan HRMS kemudian dilakukan ujiaktivitas antioksidan dengan menggunakan metode DPPH (2,2-diphenyl-1picryl hydrazyl) yang merupakan radikal sintetik yang larut dalam pelarut polar seperti metanol. Senyawa antioksidan akan bereaksi dengan senyawa radikal DPPH melalui mekanisme donasi atom hidrogen dan menyebabkan terjadinya perubahan warna DPPH dari ungu kekuning pada panjang gelombang $517 \mathrm{~nm}$ (Hanari dkk., 2005). Senyawa antioksidan memiliki peran yang sangat penting dalam kesehatan. Berbagai bukti ilmiah menunjukkan bahwa senyawa antioksidan mengurangi resiko terhadap penyakit kronis seperti kanker dan penyakit jantung. Karakter utama senyawa antioksidan adalah kemampuannya untuk menangkap radikal bebas (Prakash, 2001).

\section{METODOLOGI PENELITIAN}

\section{Alat dan bahan}

Alat-alat yang digunakan yaitu satu set peralatan destilasi, neraca analitik, ultrasonik $\left(\mathrm{Ney}^{\circledR}\right)$, oven microwave (Samsung ME109F), tabung reaksi bertutup, kertas saring Whatmann, pompa vakum, corong buchner, chamber, termometer, alat penentu titik leleh Fisher John, lampu UV (Camag ${ }^{\circledR} 254$ dan 366 nm) model UVL-56, spektrofotometer UVVisible (Genesys 10S UV-VIS v4.002 2L9N175013), spektrofotometer IR (FTIR Shimadzu, IR Prestige-21), spektroskopi NMR (Agilent $500 \mathrm{MHz}$ ), HPLC (Shimadzu LC Solution), serta alat gelas yang umum digunakan untuk sintesis, uji toksisitas dan di Laboratorium Kimia FMIPA-UR sesuai dengan prosedur kerja.

Bahan-bahan yang digunakan dalam penelitian ini adalah 1-naftaldehid (Merck), 2metoksi asetofenon (Merck), etanol absolut (Merk), natrium hidroksida, asam klorida
(Merck), hidrazin hidrat (Merck), asam asetat glasial (Merck), indikator universal, plat KLT $\mathrm{GF}_{254}$, aqua DM, aluminium foil, $n$-heksan, etilasetat, metanol, diklorometan, kloroform, larva udang, air laut, dimetil sulfoksida, dan lain sebagainya.

\section{Sintesis senyawa pirazolin}

Senyawa kalkon $(0,288 \mathrm{~g} ; 1 \mathrm{mmol})$ dan $10 \mathrm{~mL}$ etanol absolut masing-masing dimasukkan ke dalam tabung reaksi bertutup, kemudian kalkon dilarutkan dengan menggunakan ultrasonikasi sampai homogen. Setelah itu, ditambahkan hidrazin $(0,6 \mathrm{~g}, 12$ mmol) lalu dihomogenkan. Campuran tersebut ditambahkan 10 tetes asam asetat glasial kemudian diiradiasi menggunakan microwave dengan daya 180 Watt selama 4 menit. Kontrol reaksi dilakukan setiap 1 menit menggunakan KLT. Setelah reaksi selesai, campuran didiamkan hingga terbentuk endapan. Padatan yang terbentuk disaring menggunakan corong buchner dan dicuci dengan metanol dingin kemudian divakum hingga kering, pengeringan dilakukan pada suhu ruang. Selanjutnya senyawa yang diperoleh diuji kemurniannya dengan KLT, pengukuran titik leleh dan HPLC.

\section{Uji aktivitas antioksidan}

Senyawa murni yang dihasilkan dilanjutkan dengan uji aktivitas sebagai antioksidan. Pada uji ini menggunakan metode DPPH (2,2-diphenyl-1-picryl hydrazyl). Sebelumnya larutan induk dibuat dengan melarutkan sampel sebanyak $2 \mathrm{mg}$ dalam 2 $\mathrm{mL}$ metanol (konsentrasi sampel diperoleh $1000 \mu \mathrm{g} / \mathrm{mL}$ ). Sebanyak $100 \mu \mathrm{L}$ sampel dimasukkan ke dalam microplate baris A (plate terdiri dari A-H masing-masing berjumlah 12 sumur).

Sebanyak $50 \mu \mathrm{L}$ metanol dimasukkan pada masing-masing sumur pada baris B-F. Baris A dipipet sebanyak $50 \mu \mathrm{L}$ dan 
dimasukkan ke baris B,baris B dipipet 50 $\mu$ Ldimasukkan ke baris $\mathrm{C}$, dan baris $\mathrm{C}$ dipipet $50 \mu \mathrm{L}$ dimasukkan ke baris $\mathrm{D}$, hal yang sama dilakukan sampai baris F. Selanjutnya ketika sampai di baris F dipipet $50 \mu \mathrm{L}$ lalu dibuang, sehingga didapatkan konsentrasi $1000 \mu \mathrm{g} / \mathrm{mL}$, $500 \mu \mathrm{g} / \mathrm{mL}, \quad 250 \mu \mathrm{g} / \mathrm{mL}, \quad 125 \mu \mathrm{g} / \mathrm{mL}$, $62,5 \mu \mathrm{g} / \mathrm{mL}$, dan $31,25 \mu \mathrm{g} / \mathrm{mL}$ sedangkan pada baris $\mathrm{G}-\mathrm{H}$ diisi dengan metanol $50 \mu \mathrm{L}$. Baris
A-H ditambahkan dengan DPPH $80 \mu \mathrm{g} / \mathrm{mL}$ sebanyak $80 \mu \mathrm{L}$. Setelah itu diinkubasi selama 30 menit. Aktivitas penangkapan radikal diukur sebagai penurunan absorbansi DPPH dengan microplate reader dan olah data.Aktivitas antioksidan sampel ditentukan oleh besarnya hambatan serapan radikal DPPH melalui perhitungan persentase inhibisi serapan DPPH dengan menggunakan rumus :

$$
\% \text { Inhibisi }=\frac{\text { Abs. Kontrol-Abs.Sampel }}{\text { Abs.Kontrol }} \times 100 \%
$$

\section{HASIL DAN PEMBAHASAN}

Senyawa analog pirazolin yaitu 3-(2metoksi-fenil)-5-naftalen-1-il-4,5-dihidro- $1 \mathrm{H}$ pirazol disintesis melalui reaksi kondensasi aldol antara kalkon dengan dua senyawa turunan hidrazin yaitu hidrazin hidrat menggunakan katalis asam asetat glasial di bawah kondisi iradiasi gelombang mikro dengan daya 180 Watt selama 4 menit. Senyawa yang diperoleh berupa kristal putih dengan hasil rendemen yang memuaskan.

Senyawa analog pirazolin yang diperoleh tanpa dilakukan proses pemurnian karena berdasarkan uji KLT senyawa ini satu noda dan berdasarkan uji titik leleh range titik leleh dari senyawa ini 2 derajat yang menunjukkan bahwa senyawa tersebut sudah murni. Senyawa yang murni dikarakterisasi menggunakan spektroskopi UV, FTIR, dan HRMS.

Skema reaksi sintesis senyawa analog pirazolin secara umum diperlihatkan pada Gambar 1 dan reaksi pembentukan senyawa pirazolin dari kalkon dan hidrazin hidrat diperlihatkan pada Gambar 2. Senyawa analog pirazolin diuji dengan KLT dan menunjukkan satu noda, selisih titik leleh 2, maka disimpulkan senyawa tersebut murni. Selanjutnya, senyawa diidentifikasi dengan spektroskopi UV, FTIR, dan HRMS. Spektrum UV senyawa pirazolin memperlihatkan serapan maksimum pada $222 \mathrm{~nm}$ dan $296 \mathrm{~nm}$, hal ini menunjukkan bahwa senyawa pirazolin tersebut memiliki ikatan rangkap terkonjugasi.

Hasil analisis spektroskopi FTIR menunjukkan munculnya beberapa puncak yang menunjukkan vibrasi ikatan yang khas untuk senyawa pirazolin. Spektrum IR senyawa menunjukkan adanya serapan maksimum pada bilangan gelombang 3363 $\mathrm{cm}^{-1}$ yang mengindikasikan adanya vibrasi streching gugus $\mathrm{N}-\mathrm{H}$ aromatik (strong); bilangan gelombang $1596 \quad \mathrm{~cm}^{-1}$ mengindikasikan adanya streching gugus $\mathrm{C}=\mathrm{N}$ (strong). Pada bilangan gelombang $3048 \mathrm{~cm}^{-1}$, $3007 \mathrm{~cm}^{-1}, 1509 \mathrm{~cm}^{-1}$ dan $1336 \mathrm{~cm}^{-1}$ menunjukkan adanya vibrasi ikatan dari gugus $\mathrm{C}-\mathrm{H}$ aromatik, $\mathrm{C}-\mathrm{H}$ alifatik, $\mathrm{C}=\mathrm{C}$ aromatik, $\mathrm{C}-$ $\mathrm{N}$, dan pada bilangan gelombang $1239 \mathrm{~cm}^{-1}$ mengindikasikan adanya gugus $\mathrm{C}-\mathrm{OCH}_{3}$ (strong). 


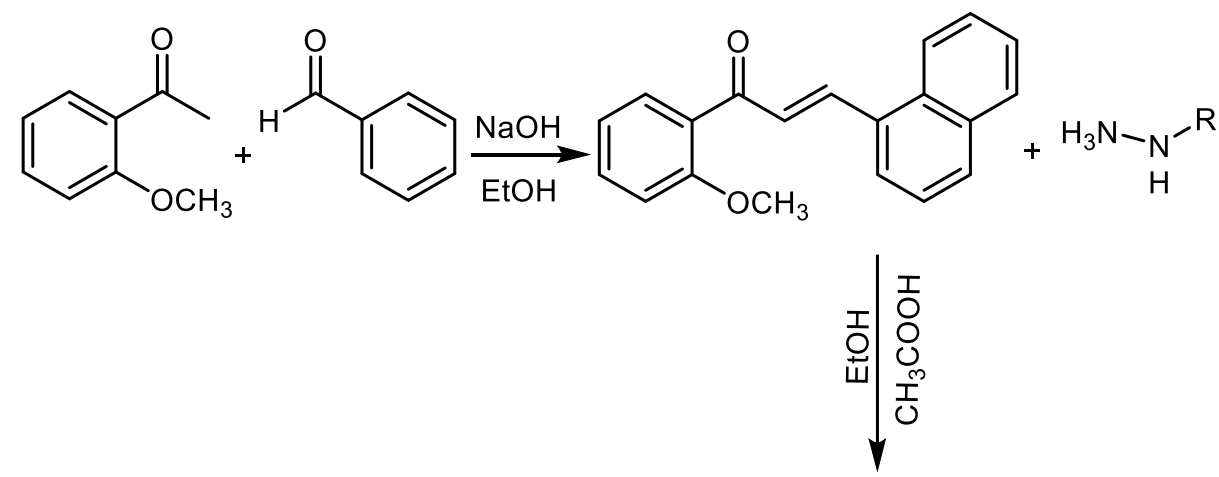

$\mathrm{R} 1=\mathrm{C} 6 \mathrm{H} 6$

$\mathrm{R} 2=\mathrm{H}$

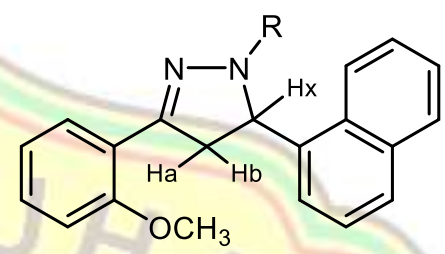

Gambar 1. Reaksi sintesis senyawa pirazolin

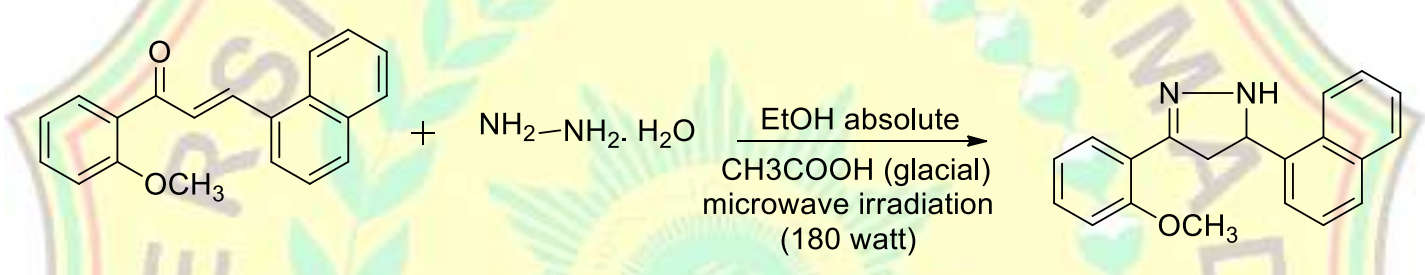

Gambar 2. Reaksi pembentukan senyawa pirazolin dari kalkon dan hidrazin hidrat

Spektrum HRMS dari senyawa senyawa pirazolin hasil sintesis memiliki pirazolin terukur sebagai $[\mathrm{M}+\mathrm{H}]^{+}$dengan $\mathrm{m} / \mathrm{z}$ aktivitas sebagai antioksidan. Hal ini 303,1492 dengan kelimpahan 100\%. Massa dikarenakan senyawa pirazolin tersebut terhitung dari senyawa yang diharapkan memiliki nilai $\mathrm{IC}_{50}<100 \quad \mu \mathrm{g} / \mathrm{mL}$ yang menunjukkan $[\mathrm{M}+\mathrm{H}]^{+}=303,1497$ dan dikategorikan bersifat aktif sebagai memiliki selisih yang kecil yaitu 0,0005 antioksidan yang dapat menghambat radikal dengan rumus molekul $\mathrm{C}_{20} \mathrm{H}_{18} \mathrm{ON}_{2}$.

\section{DPPH.}

Berdasarkan hasil uji aktivitas antioksidan menggunakan metode DPPH 
Tabel 1. Hasil uji aktivitas antioksidan senyawa pirazolin hasil sintesis.

Senyawa Struktur Senyawa $\begin{gathered}\text { Nilai IC } 50 \\ (\boldsymbol{\mu g} / \mathbf{m L})\end{gathered}$

\section{KESIMPULAN DAN SARAN}

Berdasarkan penelitian yang telah dilakukan, maka dapat diambil kesimpulan bahwa sintesis senyawa pirazolin 3-(2metoksi-fenil)-5-naftalen-1-il-4,5-dihidro- $1 \mathrm{H}$ pirazol dari kalkon dengan hidrazin menggunakan/ iradiasi gelombang mikro dengan katalis asam asetat glasial menghasilkan persen rendemen yang memuaskan. Hasil karakterisasi menggunakan spektroskopi UV, FT-IR dan HR-MS menunjukkan bahwa struktur molekul senyawa hasil sintesis sesuai dengan struktur molekul target. Uji aktivitas antioksidan menggunakan metode DPPH menunjukkan bahwa senyawa pirazolin bersifat aktif antioksidan dengan nilai $\mathrm{IC}_{50}$ sebesar $21,41 \mu \mathrm{g} / \mathrm{mL}$.

\section{SARAN}

Berdasarkan penelitian yang telah dilakukan, maka dapat diberikan saran untuk penelitian selanjutnya yaitu modifikasi struktur dengan menambahkan substituen lainnya selain gugus metoksi baik pada cincin fenil ataupun pada cincin naftalen mengingat potensi yang ada pada senyawa ini. Selain itu perlu dilakukan uji bioaktivitas lainnya seperti antiinflamasi, antimikroba, antimalaria, dan lain sebagainya guna memperoleh informasi potensi pemanfaatan senyawa lebih luas.

\section{UCAPAN TERIMA KASIH}

Ucapan terimakasih kepada Prof. Dr. Jasril, MS dan Dr. Hilwan Yuda Teruna, M. $\mathrm{Si}$, Apt yang telah membimbing penulis dari awal hingga terselesaikannya penelitian ini.

\section{DAFTAR PUSTAKA}

Arora, P., Arora, V., \& Lamba, H. S. 2012. Synthesis and Biological Activities of Some 3,5 Disubstituted Pyrazoline Derivatives of 2-acetylnaphthalene. International Journal of Pharmacy and Pharmaceutical Sciences. 4(4) : 303306.

Azarifar, D \& Shaebanzadeh. 2002. Synthesis and characterization of new 3,5dinaphtyl substituted 2-pyrazolines and study of their antimicrobial activity. Molecules. 7: 885-895.

Bagade, S. B., Chovatia, Y. S., Gandhi, S. P., \& Gorde, P. L. 2010. Synthesis and Antibacterial Activity of Some Pyrazoline Derivatives. Oriental Journal of Chemistry. 26(1) : 275-278.

Jaishree, D.M., Manoja, S.C., Balsere, N.G., \& Rajput, P.R. 2010. Synthesis and Study of Chlorosubstituted 4-Aroyl and 4Alkoyl-Pyrazolines, Pyrazoles and Their Effect on Some Flowering Plants. Indian Journal of Chemistry. 49: 505-555. 
Jayapal, M.R., \& Sreedhar, N.Y. 2010. Anhydrous $\mathrm{K}_{2} \mathrm{CO}_{3}$ as Catalyst for the Synthesis of Chalcones Under Microwave Irradiation. Journal of Pharmaceutical Science and Research. 2(10): 644-647.

Prakash, A. 2001. Antioxidant Activity. Medalion Laboratories Analitical Progress. 19(2).

Prasad, Y. R., Raharman, S. H., Kumar, Phani., \& Bhuvaneswari, K. 2010. Synthesis and Antihisteminac Activity of Novel Pyrazoline Derivatives.
International Journal of ChemTech Research. 11(2) : 16-20.

Sakthinathan, S.P., Vanangamudi, G., \& Thirunarayanan, G. 2012. Synthesis, Spectral Studies and Antimicrobial Activities of Some 2-Naphthyl Pyrazoline Derivatives. Elsevier Journal. 95: 693-700.

Singh, P., Negi, J.S., Pant, G.J., Rawat, M.S.M. \& Budakoti, A. 2009. Synthesis and characterization of a novel 2pyrazolin. Open Access Molbank M614. 